Lawrie et al (2001) have raised the question, 'Whose responsibility?' Clinicians intimidated by the practical concepts of evidence-based psychiatry need to respond by expressing their difficulties and asking for time and resources to guide them through its complexities. Easy access to summaries of evidence may be the shortterm solution, but the science of evidencebased psychiatry has to be mastered to continue practising the art of medicine. It's our responsibility.

Brown, T. \& Wilkinson, G. (eds) (2000) Critical Reviews in Psychiatry (2nd edn), p. I. London: Gaskell.

Lawrie, S. M., Scott, A. I. F. \& Sharpe, M. C. (2000) Evidence-based psychiatry - do psychiatrists want it and can they do it? Health Bulletin, 58, 25-33.

_ _ _ \& _ (200I) Implementing evidence-based psychiatry: whose responsibility? British Journal of Psychiatry, 178, 195-196.

Sackett, D., Straus, S. E., Richardson, W. S., et al (2000) Evidence-Based Medicine: How to Practice and Teach EBM (2nd edn). London: Churchill Livingstone.

A. Jha West Herts Community Health NHS Trust, Logandene, Ashley Close, Hemel Hempstead, Hertfordshire HP3 8BL

\section{Reintroduction of clozapine after diagnosis of lymphoma}

The atypical antipsychotic clozapine has been shown to be of value in some patients with treatment-resistant schizophrenia. The drug is now only used with careful blood monitoring after fatalities were noted in the early 1970s when the drug was initially released. Alvir et al (1993) estimate the incidence of agranulocytosis to be about $0.9 \%$ at 1 year. The following case demonstrates that a patient may suffer blood dyscrasias for reasons other than the known effects of clozapine and that the drug can be successfully reintroduced with a coexistent haematological malignancy.

A patient with a history of treatmentresistant schizophrenia was started on clozapine. After several months she developed asymptomatic agranulocytosis. On admission, investigations were normal apart from a bone marrow biopsy which showed agranulocytosis and mild myeloblastic changes attributed to an acute drug effect. Clozapine was ceased and short-term treatment with granulocyte colony-stimulating factor appeared to be successful.
The patient's mental state deteriorated after treatment with chlorpromazine and quetiapine. During her subsequent psychiatric admission, fevers were noted and a further general hospital admission was arranged. She was found to have severe hypercalcaemia and hyperphosphataemia and reported bone pain. Bone marrow aspirate revealed a diffuse large B-cell lymphoma, which was treated with intensive combination chemotherapy over three cycles.

The patient was initially managed with haloperidol and diazepam. Relatively large doses of these medications were used to provide sedation during the initial phases of chemotherapy. After discussion with the patient, her relatives and the treating haematology team, it was decided to reintroduce clozapine seeking better antipsychotic control. The drug was restored with good effect and continued, despite very significant neutropenia secondary to the chemotherapy.

The case illustrates that clozapine can be ceased because of suspicions that it has lead to agranulocytosis while an underlying more sinister cause is not immediately detected. Subsequently, the drug was reintroduced with good antipsychotic effect in a patient who was severely medically ill.

Alvir, J. M. J., Lieberman, J. A., Safferman, A. Z., et al (1993) Clozapine-induced agranulocytosis: incidence and risk factors in the United States. New England Journal of Medicine, 329, 162-167.

J. Hundertmark, P. Campbell Flinders Medical Centre, Bedford Park, South Australia 5042, Australia

\section{Stigma and ineffective legislation}

Further to Haghighat (2001), I would like to point out that the impact of stigmatisation is what it was when Goffman was developing his thoughts on stigma.

The impact of the the Human Genome Project potentially reveals boundless information that is stigmatising to both individual and family, in terms of employment, education and insurance. Although Haghighat refers to legislation in this area to prevent such discrimination, existing law provides little confidence in these burgeoning areas. The UK Disability Discrimination Act 1995, specifically referring to physical or mental impairment, provides little but deficiencies in the setting of discrimination against a propensity of developing a disorder in the future. Discrimination against such individuals would not be deemed unlawful. Amendments regarding this issue were discussed in both Houses of Parliament but not implemented (Nuffield Council on Bioethics, 1998). In contrast, a number of states in the USA have prohibited the use of information about employees' genetic characteristics by employers (Yesley, 1997).

In insurance, clients who have undergone genetic tests will be required to inform insurance companies of these. Proposals to avoid the unfair use of genetic information by insurance companies were announced in November 1998. Such a scheme relies on a voluntary rather than legal framework between the Department of Trade and Industry and the Human Genetics Advisory Committee (Clarke, 1995). This may do little to allay fears that an essentially profit-making business is being expected voluntarily to operate an ethical code of practice.

We may find that genetics provides a potential source of stigmatisation. As yet, the UK has few legal safeguards in place to protect individuals, who increasingly will have to manage this information carefully, rather as the 'discreditable' Goffman wrote of. Rather than legislation providing 'institutional support', the present situation serves only to propagate, in the public eye, a vision of a 'genetic underclass' (Clarke, 1995). An underclass where the stigmatising scars are invisible but their devastating effects on individual freedom are all too apparent.

Clarke, A. (1995) Population screening for genetic susceptibility to disease. British Medical Journal, 3II, 35-38.

Haghighat, R. (200I) A unitary theory of stigmatisation. British Journal of Psychiatry, 178, 207-215.

Nuffield Council on Bioethics (1998) Mental Disorders and Genetics: The Ethical Context. London: Nuffield Council on Bioethics.

Yesley, M. (1997) Genetic privacy, discrimination and social policy. Microbial and Comparative Genomics, 2, 19-35.

J. M. Clifford St Bartholomew's Higher Training Scheme, South Forest Centre, 21 Thorne Close, Leytonstone, London ElI 4HU 